\title{
Patrimonio minero y turismo de proximidad: explorando sinergias. El caso de Cardona
}

\author{
Joan Carles Llurdés
}

Universitat Autònoma de Barcelona. Departament de Geografia

joancarles.llurdes@uab.cat

\section{Inmaculada Diaz-Soria}

Université de Toulouse 2. Centre d'Études et de Recherche Travail Organisation Pouvoir (CERTOP). École Doctorale Temps, Espaces, Sociétés, Cultures (TESC)

inmaculada.diaz-soria@univ-tlse2.fr

Francesc Romagosa

Universitat Autònoma de Barcelona. Departament de Geografia

francesc.romagosa@uab.cat

\section{Resumen}

El número de experiencias de turismo de patrimonio minero en España ha experimentado un notable crecimiento durante los últimos años, contribuyendo con ello a revalorizar un recurso que ha conseguido hacerse un pequeño hueco en un contexto turístico cada vez más competitivo. Simultáneamente, también ha ido ganando aceptación el denominado turismo de proximidad, en la medida que favorece la revalorización del patrimonio local por la propia población. Partiendo de la idea de que ambas formas de turismo son complementarias, es muy lógico querer encontrar sinergias. El artículo analiza el caso concreto del Parque Cultural de la Montaña de Sal, en la antigua localidad minera de Cardona (Cataluña). Aunque con matices, los datos y el análisis realizado demuestran que Cardona ha ganado protagonismo en los últimos años en los ámbitos del turismo de patrimonio y de proximidad, con la consolidación de su oferta turística-minera.

Palabras clave: patrimonio minero; turismo de proximidad; Cardona; desarrollo local; sinergias. 


\section{Resum. Patrimoni miner i turisme de proximitat: explorant sinergies. El cas de Cardona}

El nombre d'experiències de turisme de patrimoni miner a Espanya ha experimentat un notable creixement durant els darrers anys, fet que ha contribuït a revalorar un recurs que ha aconseguit fer-se un petit forat en un context turístic cada cop més competitiu. Simultàniament, va guanyant també acceptació el denominat turisme de proximitat, en la mesura que afavoreix la revaloració del patrimoni local per la mateixa població. Partint de la idea que ambdues formes de turisme són complementàries, és molt lògic voler trobar-hi sinergies. L'article analitza el cas concret del Parc Cultural de la Muntanya de Sal, a l'antiga localitat minera de Cardona (Catalunya). Tot i que amb matisos, les dades i l'anàlisi realitzada demostren que Cardona ha guanyat protagonisme en els últims anys en els àmbits del turisme de patrimoni i de proximitat, amb la consolidació de la seva oferta turística-minera.

Paraules clau: patrimoni miner; turisme de proximitat; Cardona; desenvolupament local; sinergies.

Résumé. Le patrimoine minier et le tourisme de proximité: exploration des synergies. Le cas de Cardona

Le nombre d'expériences nationales de tourisme minier en Espagne a augmenté notablement ces dernières années. Cela a contribué à la mise en valeur de ces ressources, celles-ci ayant réussi à se faire une place dans un contexte touristique très compétitif. En même temps, le tourisme connu comme tourisme de proximité est de plus en plus reconnu. Cette forme touristique favorise la mise en valeur du patrimoine local par la population elle-même. Si l'on part de l'idée que les deux types de tourisme sont complémentaires, il est logique de tenter de trouver des synergies. L'article analyse le cas du Parc Culturel de la Montagne de Sel, dans la commune de Cardona (Catalogne), connue pour sa tradition minière. Les données et l'analyse réalisées montrent, avec des nuances, que Cardona a acquis de l'importance dans les domaines du tourisme culturel et de proximité ces dernières années, l'offre minière ayant notamment bénéficié de ce développement.

Mots-clés: Patrimoine minier; tourisme de proximité; Cardona; développement local; synergies.

\section{Abstract. Mining heritage and proximity tourism: Exploring synergies. The case of Cardona}

The number of mining heritage tourism experiences in Spain has grown significantly in recent years, thereby contributing to reappraising a resource that has managed to create a small niche in an increasingly competitive tourism context. Simultaneously, the so-called "proximity tourism" has also been gaining acceptance, as it promotes the appreciation of heritage among local people. Based on the idea that both forms of tourism are complementary, this article attempts to identify the synergies between them. The article analyzes the specific case of the Salt Mountain Cultural Park in the old mining town of Cardona, Catalonia. Although with some nuances, the data and analysis show that Cardona has gained prominence in recent years in the sphere of heritage tourism and proximity tourism through the consolidation of its mining tourism offering.

Keywords: mining heritage; proximity tourism; Cardona; local development; synergies. 


\section{Sumario}

1. Introducción 5. Resultados. El turismo de proximidad

2. La visión restringida del patrimonio en Cardona

industrial y minero

6. Conclusiones

3. El turismo de proximidad

Referencias bibliográficas

4. Cardona: de centro minero

a patrimonio turístico minero

\section{Introducción}

El número de experiencias de turismo de patrimonio minero ha experimentado un notable crecimiento en los últimos años en España, contribuyendo a la revalorización de un tipo de recurso que en determinados casos ha conseguido hacerse un pequeño hueco en un contexto turístico cada vez más competitivo. Los casos de los parques mineros de Riotinto (Huelva), Almadén (Ciudad Real), La Unión (Murcia), Andorra - Sierra de Arcos (Teruel) o Cardona (Barcelona) son buena muestra de ello (Cañizares, 2011a). Paralelamente, van ganando también cada vez más aceptación ciertas formas de turismo más o menos innovadoras, entre las cuales el denominado turismo de proximidad (Díaz y Llurdés, 2013). Y todo esto en un contexto turístico general que ha hecho del patrimonio cultural —entendido en un sentido muy amplio- uno de los recursos más utilizados por cualquier territorio; por supuesto, también por aquellos que están pasando por procesos de crisis y restructuración por la desaparición de sus antiguos monopolios productivos y la incertidumbre de qué hacer ahora. Es en esta tesitura que disponiendo de un tipo de patrimonio no muy conocido, a la vez que tampoco valorado en su justa medida, algunos territorios empiezan a poner en el «escaparate turístico» experiencias basadas en la antigua actividad industrial o minera.

Los objetivos del artículo se detallan como sigue:

- Abordar una línea de investigación que contribuya a una mejor comprensión del turismo de patrimonio minero, tomando como ejemplo el caso de Cardona.

- Analizar cómo el turismo de proximidad puede favorecer la revalorización del patrimonio local por la propia población, como un factor absolutamente necesario para una estrategia turística viable. Por lo tanto, será muy lógico explorar posibles sinergias entre ambas formas de turismo que, por supuesto, son complementarias.

- Analizar cómo algunas fuentes de información de tipo «popular» (por oposición a otras más «académicas»), han abordado el patrimonio minero y su difusión como un recurso turístico perfectamente viable.

La principal hipótesis del estudio es que la revalorización del patrimonio minero a través del turismo es un proceso que además de estar en franca 
expansión desde hace algunos años, tiene en la opción del turismo de proximidad una oportunidad para poderse consolidar a medio plazo. Aun así, sin negar dicha expansión, también es cierto que hay luces y sombras, experiencias con resultados no muy espectaculares, cuando no excesivamente modestos en muchas de ellas. Por lo tanto, un nuevo modelo de desarrollo territorial basado, en gran parte, en el turismo sería algo limitado y se necesitaría una concepción más amplia: se pasaría del patrimonio turístico al patrimonio territorial.

Finalmente, la metodología utilizada en el estudio se ha basado en:

- Una revisión de la bibliografía sobre casos nacionales de reconversión de antiguos centros mineros a parques turísticos. Su finalidad es poder comprobar en qué medida el caso de estudio de Cardona ha seguido una dinámica parecida a otros y en qué nivel se sitúa actualmente.

- Una revisión de la bibliografía publicada sobre turismo de proximidad. Su finalidad es comprobar cómo desde un punto de vista académico, es un ámbito todavía muy poco investigado en nuestro país.

- Una revisión de los números publicados en la revista Descobrir Catalunya, puesto que además de poseer un amplio fondo, puede considerarse también una publicación de tipo "popular» (y no «académica») que lleva desde 1997 fomentando el turismo de proximidad.

\section{La visión restringida del patrimonio industrial y minero}

Hace unas dos décadas aparecieron en nuestro país los primeros artículos académicos que indagaban sobre el potencial turístico del patrimonio industrial y minero, a partir de las primeras experiencias que empezaban a ponerse en marcha o cuando menos, a hablarse de ello, si bien a remolque de otros países europeos con una mayor tradición en este campo (Llurdés, 1995; Edwards y Llurdés, 1996; Llurdés, 1997; Pardo, 2002). Sin embargo, fue sobre todo durante la siguiente década cuando el número de aportaciones se incrementó significativamente, lo que sería un reflejo de dos hechos: primero, de la incorporación en el mercado turístico de territorios, a menudo de interior y con un escaso o nulo peso en el sector, que ponen en valor su patrimonio manufacturero como una vía, quizás más exploratoria que efectiva, de recuperación económica. Así, Puche et al. (2011) y Cañizares (2011b) constatan cómo ha sido especialmente a principios del siglo XXI cuando ha habido un crecimiento bastante notable del número de museos mineros en España. Por su parte, Prat (2012) proporciona un interesante análisis de la expansión espacial y temporal (de 1980 a 2010) de la oferta de turismo industrial para el caso catalán, como ejemplo de territorio con una gran tradición industrial que ha visto cómo la reconversión del sector también ha supuesto un aumento progresivo de dicha oferta. El citado análisis deja patente cómo se ha pasado de apenas 6 lugares con una cierta oferta turística de patrimonio industrial en el año 1980 a 59 en el 2010, a la vez que se observa también un aumento bastante destacado del número global de visitantes. 
El segundo hecho se refiere a la consolidación de una demanda que, a pesar de mostrar unas cifras bastante modestas, da pie a hablar de un turismo con una cierta entidad, lo que por otra parte también permite establecer sinergias con el turismo de proximidad, tal y como se analizará posteriormente. Podría afirmarse, pues, que la reconversión del patrimonio minero e industrial ha logrado abrirse camino y ha superado un periodo de ignorancia y desidia administrativa, de dificultades de tipo perceptivo, económico, legal y físico, derivadas de las dudas que supone su proceso de transformación en lugares rehabilitados para el ocio, el turismo y la difusión cultural (Pardo, 2010). Sin embargo, este relativo optimismo no debe esconder un hecho fundamental: la necesidad de reconocer que aun habiendo experiencias válidas que fundamentarían la idea de una cierta reactivación económica local o regional a partir de este patrimonio industrial y minero, tampoco habría que caer en el error de pensar que se trata de un fenómeno generalizado. De hecho, repasando las cifras de evolución de visitantes de algunos de los centros turístico-mineros más importantes de España, se observa cómo después de unos años de franca expansión (aproximadamente hasta la mitad de la primera década del actual siglo), últimamente se aprecia una cierta tendencia a la baja, en algunos casos bastante notable: por ejemplo, en Riotinto ha habido un descenso del 25\% de visitantes desde su máximo histórico, del $27 \%$ en Cardona, $41 \%$ en el MUNI, $43 \%$ en Almadén o del 55\% en Cercs (Tabla 1). Y de la misma manera que, sin ningún lugar a dudas, esto responde en gran parte al contexto de crisis general que vive el país, quizás esto también podría entenderse como una señal de que habría que poner en entredicho los verdaderos impactos derivados de este tipo de experiencias, sobre todo pensando en un contexto territorial más amplio de la escala estrictamente municipal.

A pesar de que este patrimonio tendría que merecer la misma consideración que la que tienen otros recursos patrimoniales más «tradicionales» y con un mayor reconocimiento, sería absurdo negar que esto ocurre en la práctica en todos los casos. Nadie puede poner en duda que el concepto de patrimonio se ha ido ampliando: de ser algo «sacralizado» a un determinado conjunto de objetos convertidos en referentes protegidos por los representantes de la cultura oficial (Fernández, 2006), ha pasado a englobar todo lo que sirva para reflejar una época y contribuya también a mantener viva la memoria colectiva de una comunidad y un territorio. Sin embargo, existen algunos factores en nuestro país que hacen que el patrimonio industrial y minero aún no sea reconocido en toda su amplitud, y que se pueden resumir en tres: el primero, de carácter temporal en la medida que se trata de un patrimonio bastante reciente. En este sentido, lo "patrimonial» tendría una visión restringida y diferenciaría entre lo que es más antiguo y lo que no lo es tanto. Por esta razón lo industrial correría el peligro de desaparecer porque puede ser visto como algo ordinario y no extraordinario y, en general, todo aquello que es posterior a la Revolución Industrial se ha tendido a eliminar sin valorar apenas que muchas veces este patrimonio, que a menudo ha sido visto como un estorbo, ha transformado el territorio en el que se localiza (Montilla, 2014). 
Tabla 1. Número de visitantes anuales en algunos de los principales parques mineros españoles

\begin{tabular}{rrrrrrr}
\hline & $\begin{array}{c}\text { Parque } \\
\text { Minero de } \\
\text { Riotinto }\end{array}$ & $\begin{array}{c}\text { Museo de la } \\
\text { Minería y de } \\
\text { la Industria }\end{array}$ & $\begin{array}{c}\text { Cultural de } \\
\text { la Montaña } \\
\text { de Sal }\end{array}$ & $\begin{array}{r}\text { Parque } \\
\text { Minero de } \\
\text { Almadén }\end{array}$ & $\begin{array}{r}\text { Museo de } \\
\text { las Minas de } \\
\text { Cercs }\end{array}$ & $\begin{array}{c}\text { Museo } \\
\text { Minero de } \\
\text { Priorat del }\end{array}$ \\
\hline 1992 & 7.893 & - & - & - & - & - \\
1993 & 18.538 & - & - & - & - & - \\
1994 & 23.146 & 70.129 & - & - & - & - \\
1995 & 27.690 & 62.216 & - & - & - & - \\
1996 & 28.093 & 63.847 & - & - & - & - \\
1997 & 29.349 & 74.652 & 35.796 & - & - & - \\
1998 & 35.625 & 78.900 & 70.391 & - & - & - \\
1999 & 36.621 & 85.049 & 80.569 & - & 24.266 & - \\
2000 & 42.247 & 84.109 & 66.992 & - & 39.603 & - \\
2001 & 39.774 & 89.793 & 65.711 & - & 35.400 & - \\
2002 & 42.023 & 87.870 & 70.799 & - & 42.025 & - \\
2003 & 46.626 & 85.341 & 66.680 & - & 36.454 & 8.382 \\
2004 & 44.239 & 92.520 & 71.196 & - & 36.015 & 9.396 \\
2005 & 62.492 & 95.460 & 71.314 & - & 33.175 & 8.949 \\
2006 & 66.834 & 101.109 & 71.995 & 3.898 & 33.713 & 10.817 \\
2007 & 73.899 & 105.261 & 70.541 & 14.364 & 32.419 & 11.269 \\
2008 & 78.683 & 92.144 & 67.300 & 18.121 & 32.713 & 10.441 \\
2009 & 77.403 & 96.278 & 67.935 & 16.257 & 29.632 & 11.868 \\
2010 & 69.387 & 85.000 & 66.390 & 14.952 & 27.512 & 7.133 \\
2011 & 73.149 & 86.227 & 61.787 & 12.703 & 23.629 & 9.984 \\
2012 & 62.902 & 70.109 & 56.779 & 12.184 & 18.942 & 11.003 \\
2013 & 58.775 & 61.689 & 58.210 & 10.190 & 18.773 & 9.980 \\
\hline
\end{tabular}

Fuente: García et al. (2013), Cañizares (2011a), y gerencias del Parque Cultural de la Montaña de Sal de Cardona, Museo de las Minas de Cercs, Parque Minero de Almadén y Museo Minero de Bellmunt.

El segundo factor se refiere a una cuestión de contenido. A pesar del innegable avance que ha habido en cuanto a sensibilización y reconocimiento hacia lo industrial y minero (p. ej. Álvarez, 2007; SEDPGYM, 2008), también es cierto que hasta hace muy poco no ha habido el suficiente interés, primero popular y comunitario (desde abajo) y más tarde también de las administraciones (desde arriba), para sentar unas bases realmente viables en lo que se refiere a las actuaciones de restauración, conservación y puesta en valor de este patrimonio. Aun así, y en descargo de esto último, habría que mencionar algunas iniciativas legislativas de protección a nivel estatal como las declaraciones de Bienes de Interés Cultural (Magán, 2005), el Plan Nacional de Patrimonio Industrial (IPCE, 2011) o la creación de redes asociativas de colaboración (en Cataluña sería el caso de la XATIC —o Red de Turismo Industrial de Cataluña- y el MNACTEC - Museo de la Ciencia y de la Técnica de Cataluña). Asimismo, no hay que olvidar la presentación de algunas candidaturas de con- 
juntos industriales y mineros a la declaración de Patrimonio de la Humanidad (Llurdés, 2001). Sin embargo, en lo que se refiere a esta cuestión específica, el número de conjuntos industriales y mineros incluidos en esta prestigiosa lista es bastante escaso, si se compara con el resto de elementos patrimoniales de categorías más «estándares». En otras palabras, ¿por qué nadie dudaría en asignar la etiqueta de "patrimonio" a un castillo, recinto amurallado, núcleo histórico, palacio, monasterio o catedral y en cambio, hacer lo mismo con un antiguo conjunto fabril o una explotación minera parecería algo, cuando menos, «llamativo»? Lo que sucede es que lo primero es visto como más "normal», en consonancia con los parámetros de lo que es un producto estándar de turismo cultural y en cambio, lo segundo no deja de ser algo novedoso, aún hoy día, para el gran público.

El tercer factor al que se hacía referencia es de naturaleza paisajística. Si se parte de la idea de que un paisaje es una construcción social y el testigo de la actividad humana en el entorno, habrá que reconocer que debería formar también parte de la memoria colectiva de la comunidad local, por lo que es absolutamente necesario abrir la puerta a aquellos «otros» paisajes que se hallan fuera de las fronteras de lo que habitualmente se concibe como tales (Nogué, 2007, 2008). Desde este punto de vista, en algunos casos, sobre todo relacionados con la actividad minera, ciertos territorios que durante décadas han soportado una actividad extractiva tan intensa como a la vez monopolizadora poseen, además de un patrimonio material productivo, otro de tipo paisajístico que forma parte también de su propia historia y que podría ser puesto en valor. En esta línea, si se da por hecho que una excursión, un viaje turístico, también implica un cierto sentido de la curiosidad por ver aquello que se desconoce o de lo que se tiene una vaga referencia, ¿qué menos que pasear y contemplar por uno de estos «otros» paisajes? Por ejemplo, en el caso de algunos recintos mineros a cielo abierto (Riotinto, Huelva) y también en aquellos otros que tratándose de minería subterránea dejan una profunda «huella» en su entorno (p. ej. los centros mineros de potasa de la comarca de El Bages, en la Cataluña central), esta idea podría ser muy válida. Al fin y al cabo, lo más probable es que sea muy poca la gente que conozca con detalle los impactos que en el entorno de un lugar se han derivado de la antigua actividad de una fábrica o mina.

De la misma forma que tradicionalmente se ha valorado un paisaje por su belleza y ciertos atributos (formas, colores, tonalidades), ahora también se tiende a valorar más determinados paisajes transformados por una actividad humana a priori más sostenible y «bucólica» (por ejemplo, un paisaje agrario), reconociendo a la vez que el paisaje es un concepto cargado de mucha subjetividad, entonces ¿por qué no valorar también positivamente un paisaje minero aunque a primera vista nos pueda parecer algo sucio, desordenado, abandonado e incluso contaminado? Si como se decía más arriba, un turista es, antes que nada, curioso, entonces ¿por qué tendría que dejar de visitar un entorno minero? (Llurdés, 1994).

A pesar de lo expuesto, y aunque con matices, dudas y otras consideraciones que se puedan plantear, en los últimos años, se ha ido consolidando la idea de 
patrimonio como algo mucho más amplio de lo que habitualmente ha englobado. Además, también somos testigos de cómo el territorio ha ido ganando protagonismo, no solo como sustento o base de las actividades productivas sino también como lugar en el que reencontrar unas singularidades locales, diferenciadoras, que antes pasaban desapercibidas (por la comunidad local), cuando no eran despreciadas (por agentes externos), y que en este nuevo contexto pueden ser ahora clave en lo que se ha venido denominando «desarrollo endógeno»: de un "patrimonio cultural» se pasa a un "patrimonio territorial», siendo el territorio un recurso en sí mismo y no simplemente un "contenedor» (Benito, 2002; Pardo, 2008). En otras palabras, se pasa de una lectura exclusivamente turística, cultural, del patrimonio, visto de una forma más bien aislada, a otra propiamente geográfica en la que este patrimonio debe formar parte de una estrategia de desarrollo más global, sin que bajo ningún concepto quede desligado del contexto territorial en el que se inscribe. Y puesto que el turismo está llamado a ser uno de los principales pilares económicos de cualquier territorio, ¿qué menos que tener en cuenta la revalorización turística de este patrimonio de «segundo nivel» en un mercado cada vez más complejo, fragmentado, competitivo, cambiante y en el que la «turistificación» o si se quiere, la famosa "mirada turística» que mencionaba Urry (1990) y más recientemente Urry y Larsen (2012), llega a todas partes?

\section{El turismo de proximidad}

Partiendo de la tesis básica de que la actividad turística está ligada a la voluntad de ruptura con el entorno habitual (OMT, 2008), con las prácticas más cotidianas, hay que reconocer que el turismo también ha evolucionado al mismo tiempo que conceptos como cotidiano y habitual (Díaz y Llurdés, 2013). Los avances en materia de medios de transporte y de comunicación a lo largo del pasado siglo xx han acelerado los intercambios de información a escala mundial, de modo que nos encontramos actualmente en un contexto en el que los flujos globales son continuos e inmediatos, contribuyendo a la transformación del espacio cotidiano del individuo (Govers et al., 2008). Igualmente, conceptos como los de proximidad y distancia se han desligado de su dimensión puramente geográfica y se relacionan más ahora con la noción de familiaridad. En este sentido, geógrafos y sociólogos han teorizado sobre esta nueva dimensión de la proximidad definiéndola como algo complejo, con una doble dimensión física y abstracta (Boschma, 2004): física porque la proximidad geográfica, vinculada a la distancia en kilómetros, aún persiste y también es abstracta por cuanto hablamos de la proximidad en términos de familiaridad, siendo esta algo difícil de medir, ya que se basa en percepciones subjetivas.

En este contexto, aquello que es conocido y desconocido ha ido desligándose de lo que es estrictamente la proximidad geográfica. Partiendo de la idea de que en turismo lo desconocido genera deseo de conocimiento, ¿̨cómo habría que interpretar esto cuando lo desconocido lo encontramos, precisamente, dentro de un cierto umbral de proximidad geográfica? Siguiendo el concepto 
de alteridad propuesto por Baudrillard y Guillaume (1994), podría decirse que aún existen formas de alteridad más cercanas de lo que nos pensamos. Y es en esta búsqueda de la alteridad que algunos espacios de proximidad geográfica se revelarían como nuevas terrae incognitae, contexto en el que el sector turístico habría identificado esta oportunidad, lo que daría pie al desarrollo de una cierta oferta de turismo de proximidad. En un momento de homogeneización cultural global y de reinvención de la industria turística para abarcar una demanda que no encuentra el atractivo en las fórmulas turísticas convencionales, y que busca formas alternativas de viajar, una propuesta que permita el descubrimiento del propio entorno y de su territorio más próximo aparece como una oportunidad. Si uno de los motores del turismo es la curiosidad, esta forma de «descubrir» territorios más cercanos — en términos de cercanía geográfica- se ha de ver como intrínsecamente turística, también en un contexto en el que seguramente estemos más familiarizados con culturas lejanas y muy diferentes de la nuestra que con nuestros propios vecinos.

Este turismo se enmarcaría en un contexto de búsqueda de nuevos mercados. Por un lado, podría explicarse por qué, como ya hemos comentado, el espacio de proximidad geográfica se ha convertido en algo atractivo por ser, en parte y todavía, desconocido. Y por otro, el turista actual ya no cree que sea posible descubrir algo puramente «auténtico» y buscaría la autenticidad en su experiencia personal (Uriely, 2005). Y esta experiencia puede responder a la voluntad de querer conocer mejor el territorio en el que uno vive o próximo a su lugar de residencia habitual, o simplemente la experiencia puede estar ligada a la temática de la actividad y el entorno (descubrimiento de lugares «diferentes», elementos insólitos y/o la posibilidad de llevar a cabo actividades fuera de lo común). Podría decirse, pues, que este turismo ayudaría a conciliar conceptos que en principio, pueden parecer incompatibles con la visión más tradicional que se tiene del sector, como son los de proximidad y cotidianeidad. Además, por cuanto no habría que esperar tampoco un enorme impacto económico de este turismo - la necesidad imperiosa de ser realista y a la vez prudente- parecería como si con el fomento del turismo de proximidad se quisiera avanzar hacia la «autodestrucción» del sector (Canalís, 2009). Y es que hay que tener presente que en la medida que la industria turística se basa, en gran parte, en las pernoctaciones generadas (como una de las partidas más significativas de todo viaje turístico), en este turismo estas no están garantizadas, justamente porque la pernoctación suele ir asociada a la superación de un umbral mínimo de distancia. Por este motivo, el concepto mismo de turismo de proximidad se ve a menudo cuestionado (Michel, 2012). En este sentido, quizá se podría pensar en estas actividades como parte de una forma de ocio de proximidad, entendiéndose por ocio una parte del tiempo libre elegida libremente, desinteresada, que proporciona placer, con una dimensión más bien individualista (Bessière, 2000; Dewailly y Flament, 1993) y de proximidad cuando ese ocio se practica bien en la localidad de residencia, bien en sus proximidades. Sin embargo, este artículo se refiere a un turismo de proximidad dado que, aunque la visita a los espacios mineros por parte de un público de proximidad forme 
parte del tiempo libre del individuo y estos espacios se encuentren cercanos al lugar de residencia, las prácticas que realiza no difieren de las de aquellos que sí son considerados turistas, según la definición más clásica.

Esta definición consideraría turistas solo a los visitantes que pernocten en el destino. En consecuencia, el público de proximidad formaría parte del grupo de los excursionistas en las estadísticas oficiales y no sería considerado como turista. Sin embargo, como algunos estudios demuestran, diferenciar entre turistas y excursionistas que visitan un espacio concreto no es particularmente útil para distinguir las motivaciones, las experiencias, los impactos y beneficios de la visita (Prentice et al., 1998). Es decir, para un parque minero el hecho de diferenciar aquel individuo que pernocta de aquél que no lo hace no tiene gran importancia, solamente la tiene el visitante en sí mismo. Si este artículo se refiere a un turismo de proximidad es porque el visitante de proximidad hace lo mismo que cualquier otro visitante. Si el resto de visitantes está haciendo turismo, el visitante de proximidad que esté descubriendo ese espacio estará haciendo también turismo, aunque en su caso, de proximidad, porque su desplazamiento habrá sido más corto. En ambos casos, el descubrimiento del patrimonio habrá sido la motivación principal, y sin embargo, para el visitante de proximidad, este patrimonio tiene o puede tener una importancia más personal puesto que a priori forma parte de un pasado más directo o, cuando menos, más cercano. De este modo, este atractivo puede ser explotado para la captación de estos visitantes y la revalorización del patrimonio.

Dejando de lado discusiones conceptuales, cualquier estrategia de desarrollo local que considere el turismo y el patrimonio (tangible e intangible, construido y paisajístico), habrá de ser capaz de implementar iniciativas que tengan un triple objetivo: primero, que sirvan para atraer turistas, cuantos más mejor y sin importar su lugar de procedencia pero también, y sobre todo, del propio territorio (entendido a una escala regional); segundo, para recuperar y poner en valor un determinado patrimonio antes de que se pueda perder de forma irreversible; y tercero, que sirva de palanca para que la población local pueda ver su patrimonio desde otra perspectiva radicalmente diferente a como lo ha estado viendo durante años, y lo que es más importante, que este patrimonio deje de ser un elemento pasivo para pasar a convertirse en un activo importante. Es en este contexto que es más visible y factible el turismo de proximidad como una estrategia de reactivación económica, por cuanto para que ello tenga más viabilidad, tiene que haber un proceso de reapropiación de la memoria y del patrimonio local, con el objetivo de recuperar y fortalecer la identidad. Aplicando esta visión al caso de estudio del artículo, el turismo basado en el patrimonio industrial y minero ha contribuido en algunos lugares a crear una nueva identidad, pasando de ser espacios "proscritos» (rutinarios, despersonalizados, grises y monótonos) a valorarse como lugares turísticos, de ocio y recuperación cultural (Prat y Cànoves, 2012).

Así, el turismo de proximidad vendría a ser una forma «transversal» de turismo, por supuesto compatible con otras opciones culturales (en un sentido genérico) y mineras y industriales (más específicamente). También encajaría 
bastante con el concepto de turismo de interior ya que aplicado a numerosos territorios en los que la componente del turismo más estrictamente "productivo» es lo habitual, aquí primaría más bien una visión integradora basada, precisamente, en el territorio (Díez, 2012) y en la identidad (Cànoves et al., 2014). En otras palabras, el turismo de lo ordinario (entendido como la posibilidad de redescubrir un espacio geográficamente cercano y lejano desde el punto de vista de los vínculos personales) transformaría el desplazamiento en una búsqueda del emplazamiento (Aguas y Gouyette, 2011).

\section{Cardona: de centro minero a patrimonio turístico minero}

El núcleo de Cardona es, actualmente, uno de los puntos turísticos de mayor interés en el contexto de una comarca - El Bages - que, a pesar de su potencial (por recursos, historia, paisaje, patrimonio, comunicaciones, accesibilidad, etc.), no acaba de despegar y situarse en el panorama turístico de Cataluña con un mayor peso del que tiene hoy día. Seguramente, uno de los factores que ha contribuido a ello es el hecho de tener una marca territorial poco consolidada en el contexto catalán; por ejemplo, Colom (2012) ya remarcaba en un trabajo sobre marcas turísticas la «invisibilidad» de la marca Catalunya Central, y cómo no ha conseguido dotarse de una imagen potente a pesar de ser un territorio paisajísticamente variado, localizarse cerca de Barcelona y reunir algunos recursos de cierta talla (como la montaña y el monasterio de Montserrat, con más de dos millones de visitantes anuales). Este podría ser un buen ejemplo de cómo a pesar de que el proceso de difusión del turismo se ha extendido por todo el territorio catalán, también es cierto que lo ha hecho de manera irregular. Las diversas políticas públicas y las iniciativas privadas que se han llevado a cabo han supuesto una esfuerzo importante en pro de la creación de nuevos productos turísticos capaces de dinamizar el territorio y sin embargo, en algunos casos no se ha conseguido el objetivo de aparecer en el mapa de los destinos turísticos catalanes (Coma, 2014; López Palomeque y Font, 2014).

En este contexto turísticamente «modesto», el caso de Cardona podría ser considerado una excepción. Pero antes de llegar a su actual nivel de desarrollo turístico, hay que recordar que hasta hace poco más de dos décadas, fue uno de los centros mineros de la comarca (de extracción de potasa), actividad que sigue estando presente en tres municipios más (Súria, Sallent y Balsareny), a través de la empresa Iberpotash (Figura 1). Sin embargo, en el caso de Cardona, y a diferencia de los otros tres, la minería ha sido una actividad con mucha más tradición histórica puesto que antes del inicio de la extracción de potasa, este núcleo ya era conocido desde tiempos medievales por la explotación de la sal, aunque no fue hasta 1931 cuando empezó la actividad minera en condiciones realmente industriales. Por supuesto - y como en otros centros minerosesto supuso un enorme crecimiento demográfico, sobre todo motivado por movimientos migratorios, especialmente del sur de España.

Las cifras hablan por sí solas: se pasa de poco más de 4.800 habitantes en 1930 a superar los 6.500 en 1936, con un crecimiento del 36\%. Después del 


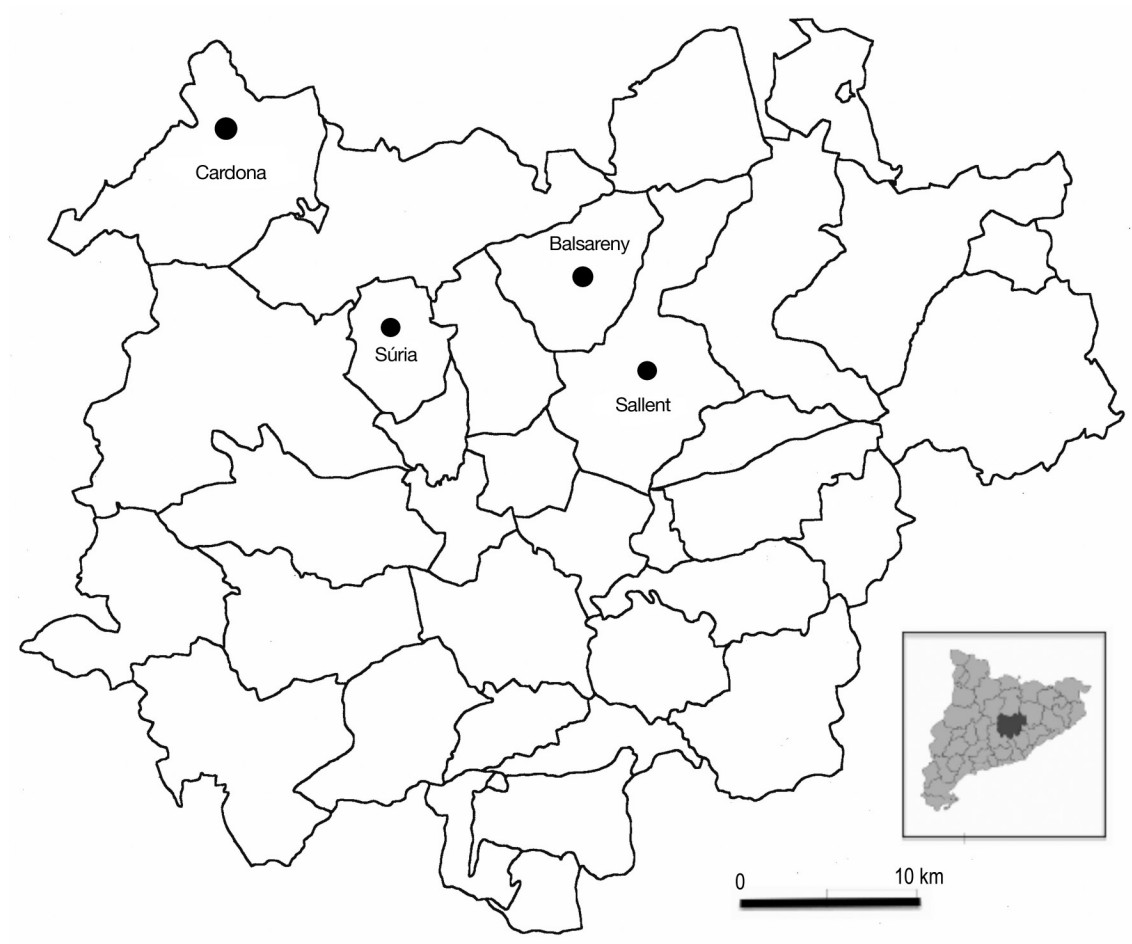

Figura 1. Localización de los núcleos mineros en la comarca de El Bages (Cataluña).

Fuente: elaboración propia.

paréntesis de la guerra civil española, el aumento poblacional continuó hasta alcanzar un máximo histórico en el año 1960 (7.885 habitantes); a partir de ahí se inició un cierto declive demográfico (que no económico) puesto que la implementación de procesos de modernización y mecanización de las tareas productivas hizo innecesaria más mano de obra, sobre todo la no cualificada. Sin embargo, este proceso de regresión demográfica se acentuó con el cierre de la mina en 1990 (motivado por los altos costes económicos y las dificultades técnicas y de seguridad que suponía la continuidad de la actividad minera). Para hacerse una idea, en el momento del cierre la última empresa concesionaria -Ercros - empleaba directamente 515 trabajadores lo que, inevitablemente, en un núcleo de poco más de 6.400 vecinos habría de tener un enorme impacto laboral, económico y social. Desde entonces, y a día de hoy, el municipio ha perdido un $23 \%$ de sus vecinos (un 1\% anual), pasándose de los casi 6.500 habitantes en 1991 a los 5.006 (padrón municipal de 2013). Por otro lado, esta es una evolución contraria a la que ha seguido el conjunto de la comarca ya que desde principios de la década de 1990 su población ha aumentado prácticamente año tras año, pasando de 152.577 habitantes (1990) a 185.718 (2013). 


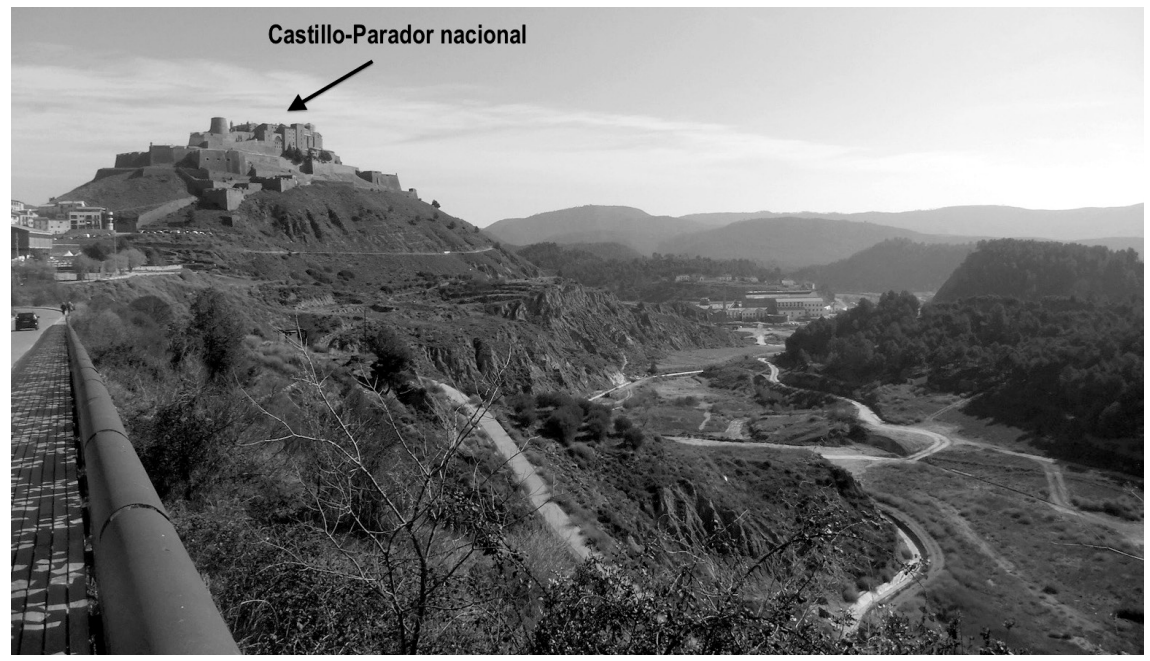

Figura 2. El castillo-parador de Cardona.

Fuente: archivo personal Joan C. Llurdés.

Además de la merma de población (básicamente por emigración) también hay que tener en cuenta el proceso irreversible de envejecimiento demográfico, a la vez que también ha desaparecido la tradicional autocontención laboral típica en municipios mineros. Y en lo que se refiere a la estructura económica, se ha seguido una evolución similar a la de otros municipios en situación de crisis industrial: la desaparición del antiguo monopolio minero ha dejado paso a un incremento del peso del sector servicios en general - modesto pero progresivo- y un papel cada vez más destacado del turismo en particular, en aquellas modalidades en las que la tipología de los recursos existentes en el territorio pueda garantizar un cierto éxito desde su inicio.

Efectivamente, después del cierre de la mina, poco tardó Cardona en apostar por el turismo como sector a potenciar, dentro de un conjunto más amplio de medidas diversas destinadas a la diversificación del tejido productivo. Sin embargo, como estas no han tenido el impacto esperado, es indudable que desde hace unos cuantos años el principal motor económico del municipio es el turismo. En 1997 se creó la empresa municipal Sal Roja S. L. con la finalidad de hacer realidad un mayor impacto de esta actividad en el municipio, la cual en 2005 pasó el testigo a la fundación privada Cardona Histórica, cuya principal función ya no es, a diferencia de la anterior, vender únicamente el recinto minero, sino más bien el municipio en su totalidad. En este sentido, hay que puntualizar que la introducción del turismo no se inició desde cero ya que el núcleo contaba con un cierto reconocimiento, al disponer de un casco antiguo bastante interesante y estar coronado por un castillo medieval en un emplazamiento impresionante, en el que se encuentran un Parador Nacional (desde 1976) y una colegiata románica de gran interés arquitectónico (Figura 2). Aun 


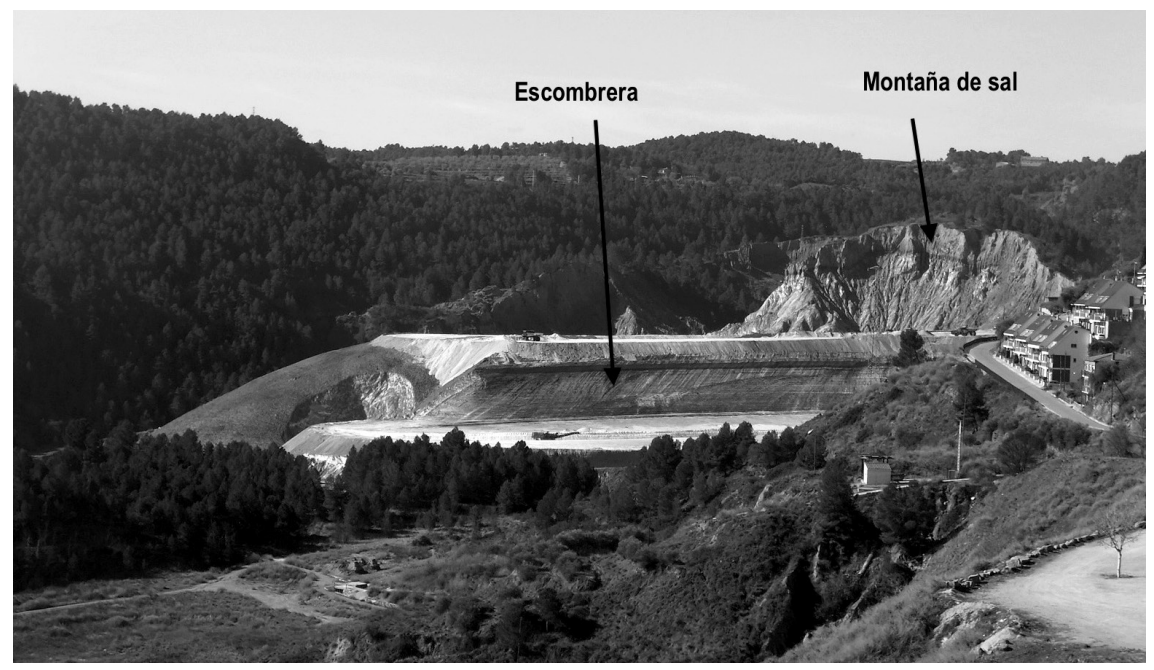

Figura 3. La montaña de sal de Cardona (junto a una escombrera minera).

Fuente: archivo personal Joan C. Llurdés.

así, con toda seguridad, el recurso estrella sigue siendo la reconversión turística de la antigua mina, que desde 1997 está abierta al público, por lo que pasaría por ser una de las minas turísticas más veteranas del país (en el año 2000 pasó a denominarse Parque Cultural de la Montaña de Sal). A grandes rasgos, el producto turístico consiste en visitar las instalaciones de uno de los pozos, con un área museográfica que ocupa algunos de los antiguos espacios productivos en superficie, así como lo que sin duda se trata del elemento más relevante de la visita: el interior de la llamada "Montaña de sal» (Figura 3) o lo que es lo mismo, un afloramiento superficial de las capas de sal que existen en el subsuelo y que alcanza una altura de un centenar de metros. Su relevancia descansa, en primer lugar, en ser un fenómeno geológico muy inhabitual, y segundo, y especialmente, en la posibilidad de visitar su interior por un recorrido de unos $500 \mathrm{~m}$ de largo, lo que sin lugar a dudas lo convierte en un recurso muy diferente a todo lo demás y a la vez diferenciador con respecto a otros parques que basan su interés en el patrimonio minero stricto sensu.

Así, aquello que empezó siendo un recurso más, expuesto en el «escaparate turístico», quizás sin una idea muy precisa de lo que se podía hacer con él y esperar de él, ha acabado siendo el principal elemento por el que Cardona ha logrado situarse en el mapa turístico catalán, a la vez que hacerse un hueco en un mercado en el que por la propia dinámica negativa del sector industrial y minero del país, han ido apareciendo más iniciativas de este tipo. Muestra de ello es que este recurso es, junto al castillo medieval antes mencionado, la principal imagen publicitaria de Cardona en la prensa escrita. El éxito (relativo o no) de esta iniciativa se traduce en una cifra de visitantes que ronda los 60.000 
en los últimos años, aunque con algún pico cercano a los 80.000, y habiéndose situado en el mismo nivel de Riotinto —el recinto turístico-minero «decano» en España- y el Museo de la Minería y de la Industria de El Entrego (ver anterior Tabla 1).

\section{Resultados. El turismo de proximidad en Cardona}

\subsection{La demanda turística}

Si analizamos las estadísticas de Cardona relativas al número y a la procedencia de los visitantes entre 2005 (primer año con cifras desglosadas disponibles) y 2013, se pueden extraer los siguientes datos:

- Total de visitantes en el período considerado: 298.303.

- Total de visitantes nacionales: 270.329 (90,6\%).

- Total de visitantes de Catalunya: 249.300 (83,5\% sobre el total y el 92,2\% sobre el total de visitantes nacionales).

- Comarca catalana que más visitantes aporta: El Barcelonès (106.992, un $35,8 \%$ del total y un $42,9 \%$ del total de visitantes de Cataluña).

En este período, Cardona se ha convertido en un destino turístico eminentemente "catalán» en el contexto estatal, al proporcionar el 92,2\% de los visitantes. Además, en gran medida se trata de un destino bastante "barcelonés» en la medida que la provincia supone casi el $68 \%$ de los visitantes y dentro de esta, solo cinco comarcas representan casi el $87 \%$ del total. Por supuesto son aquellas más pobladas las que aparecen en la lista (aquí faltaría El Maresme, que por poco no llega a los 10.000 visitantes para que se haya incluido en esta estadística) (Tabla 2).

En cierto modo, teniendo en cuenta el contexto turístico catalán general (con un predominio bastante abrumador de las opciones de litoral y montaña)

Tabla 2. Desglose de la procedencia de visitantes al recinto minero de Cardona (2005-2013)

\begin{tabular}{lrlrlr}
\hline \multicolumn{1}{c}{ Provincia } & Número & \multicolumn{1}{c}{ Comarca (1) } & Número & \multicolumn{1}{c}{ País (2) } & Número \\
\hline Barcelona & 202.027 & El Barcelonès & 106.992 & España & 270.329 \\
Tarragona & 16.676 & El Vallès Occidental & 25.798 & Francia & 8.963 \\
Girona & 15.999 & El Baix Llobregat & 16.917 & Reino Unido & 3.626 \\
Lleida & 14.598 & El Bages & 15.399 & Estados Unidos & 2.377 \\
-- & -- & El Vallès Oriental & 10.406 & -- & -- \\
Total & 249.300 & Total & 175.496 & Total & 285.295 \\
Total absoluto & 298.303 & Total absoluto & 298.303 & Total absoluto & 298.303 \\
\hline
\end{tabular}

Fuente: Parque Cultural de la Montaña de Sal de Cardona.

(1) Solo se incluyen las comarcas que superan los 10.000 visitantes.

(2) Solo se incluyen los países que superan los 2.000 visitantes. 
Tabla 3. Perfil de los visitantes al recinto minero de Cardona (2005-2013)

\begin{tabular}{lrrrrrrrrrr}
\hline \multicolumn{1}{c}{ Perfil de visitantes } & 2005 & \multicolumn{1}{c}{2006} & \multicolumn{1}{c}{2007} & 2008 & 2009 & \multicolumn{1}{c}{2010} & 2011 & \multicolumn{1}{c}{2012} & \multicolumn{1}{c}{2013} & \multicolumn{1}{c}{ Total } \\
\hline INDIVIDUAL & 37.995 & 39.287 & 37.754 & 34.498 & 38.278 & 40.046 & 36.792 & 34.390 & 35.559 & 334.599 \\
Adulto & 28.509 & 29.199 & 28.102 & 25.513 & 25.636 & 26.486 & 23.873 & 22.551 & 23.479 & 233.348 \\
Jubilado & 3.443 & 3.501 & 4.095 & 4.087 & 5.415 & 5.893 & 6.064 & 5.475 & 5.129 & 43.102 \\
Niño & 6.043 & 6.587 & 5.557 & 4.898 & 5.295 & 6.945 & 6.475 & 6.023 & 6.537 & 54.360 \\
Menor & - & - & - & - & 1.932 & 722 & 380 & 341 & 414 & 3.789 \\
\hline GRUP0 & 33.319 & 32.708 & 32.787 & 32.802 & 29.657 & 26.344 & 24.995 & 22.389 & 22.651 & 257.652 \\
Grupo escolar & 17.385 & 18.377 & 16.120 & 15.869 & 15.145 & 14.115 & 13.681 & 12.736 & 10.962 & 134.390 \\
Grupo adulto + 3 $3^{\text {a edad }}$ & 15.934 & 14.331 & 14.854 & 14.800 & 12.760 & 10.457 & 10.149 & 8.593 & 10.605 & 112.483 \\
Acompañantes grupos & -- & -- & 1.813 & 2.133 & 1.752 & 1.772 & 1.165 & 1.060 & 1.084 & 10.779 \\
\hline Total & 71.314 & 71.995 & 70.541 & 67.300 & 67.935 & 66.390 & 61.787 & 56.779 & 58.210 & 592.251 \\
\hline
\end{tabular}

Fuente: Parque Cultural de la Montaña de Sal de Cardona.

Tabla 4. Tipo de pernoctación de los visitantes al recinto minero de Cardona (2005-2013)

\begin{tabular}{lrrrrrrrrrr}
\hline Tipo de pernoctación & 2005 & \multicolumn{1}{c}{2006} & \multicolumn{1}{c}{2007} & \multicolumn{1}{c}{2008} & 2009 & 2010 & 2011 & 2012 & 2013 & Total \\
\hline N/S - N/C & 1.980 & 14.461 & 1.987 & 1.913 & 1.149 & 1.025 & 904 & 873 & 1.536 & 25.828 \\
No pernocta & 24.652 & 19.628 & 23.634 & 23.382 & 23.155 & 20.890 & 20.302 & 18.126 & 21.001 & 194.770 \\
Sí pernocta & 8.075 & 7.876 & 8.779 & 9.119 & 8.535 & 7.771 & 8.290 & 7.429 & 7.967 & 73.841 \\
Vive en Cardona & 348 & 384 & 443 & 567 & 387 & 448 & 319 & 539 & 429 & 3.864 \\
Total general & 35.055 & 42.349 & 34.843 & 34.981 & 33.226 & 30.134 & 29.815 & 26.967 & 30.933 & 298.303 \\
\hline
\end{tabular}

Fuente: Parque Cultural de la Montaña de Sal de Cardona.

y también el específicamente comarcal (El Bages), estos valores se nos antojan muy lógicos. Y aun más si la comarca está muy bien comunicada con el área metropolitana y la proximidad física de Cardona con los principales centros emisores de los visitantes que recibe, no es tanta como para disuadir a mucha gente que no se desplace.

Por otra parte, en cuanto al perfil de los visitantes que se desplazan a Cardona (Tabla 3) predomina el individual, que se ha mantenido relativamente estable durante el período estudiado (una diferencia del 14,1\% entre el mejor y el peor año). En cambio, los grupos de visitantes han ido disminuyendo año tras año (con un diferencial del 32,8\%), lo que es atribuible, por parte de la gerencia del Parque Cultural, a los efectos de la crisis económica que vive el país (las visitas escolares se han reducido en un 40,3\%, mientras que las de la tercera edad lo han hecho en un $33,4 \%$, aunque con un repunte negativo del $46 \%$ en 2012). Por supuesto que, tanto de la proximidad de la mayoría de los visitantes como de su perfil, se deriva que solo una cuarta parte de ellos pernoctaran en Cardona (quizás podría ser un poco más, puesto que hay un 8,6\% de respuestas no definidas) (Tabla 4). 


\subsection{Análisis de la oferta turística desde la óptica de la "proximidad»}

Los párrafos anteriores han tratado de reflejar de qué modo se manifiesta la «proximidad» de Cardona como destino turístico a partir de un breve análisis de la demanda. Llegados a este punto, convendría también hacer lo mismo con la manera cómo aparece promocionada en determinadas fuentes de información. Para ello se ha elegido la única revista especializada explícitamente en turismo de proximidad, Descobrir Catalunya. Se trata de una publicación que lleva ininterrumpidamente apareciendo en los quioscos desde la primavera de 1997 (habiendo llegado al número 200 en octubre de 2014), y sin lugar a dudas se puede considerar la revista de temática geográfica y turística más importante de los territorios de lengua catalana. El hecho de haber elegido esta revista en concreto no es casual: además de su extenso fondo bibliográfico en estos diecisiete años de existencia, se presenta como promotora del turismo de proximidad, entendido como el turismo realizado dentro del ámbito de la lengua catalana por los propios residentes de este ámbito y, como muestra de esta concepción turística de proximidad, el subtítulo de la revista es muy indicativo: «Descubre tu país como nunca antes lo habías visto». Así pues, las actividades, los recursos turísticos, las informaciones, etc., que aparecen en la revista se promocionan pensando, más bien, en un mercado de proximidad ${ }^{1}$.

El análisis ha consistido en una revisión de los números publicados desde su inicio hasta el mes de julio de 2014, lo que equivale a un total de 197 números. El objetivo de esta revisión es doble: primero, ver cómo a finales de los años noventa se promocionaba el territorio catalán a su potencial «público» más próximo y de qué forma Cardona empezaba a aparecer en este «escaparate», en un contexto en el que, recordémoslo, las alternativas turísticas diferentes de otras más habituales tenían poco reconocimiento entre el gran público. Por su parte, el segundo objetivo ha sido comprobar si, una vez que Cardona se ha consolidado como destino en el mercado turístico catalán después de más de una década y media en funcionamiento, ha merecido una mayor atención en la revista. Al fin y al cabo, estos últimos años responden perfectamente a la concepción de un contexto en el que el turismo ha llegado a todas partes, y ha abrazado también un sinfín de recursos y actividades hasta hace poco relativamente conocidos.

De los resultados obtenidos se constata, en primer lugar, un importante aumento de la presencia de Cardona en los números de los últimos cuatro años analizados, después de un período de una casi total ausencia a lo largo de la primera década del siglo XXI, que a su vez venía precedida de unas cuantas apariciones en los primeros años de existencia de la revista (la

1. Como muestra de implicación en esta forma de turismo, el mismo grupo editorial de la revista Descobrir Catalunya ha iniciado en octubre de 2014 la publicación de una nueva revista llamada Experiències, dedicada al turismo experiencial pero siempre acotado en este mismo ámbito territorial. Este compromiso justifica, a nuestro juicio, su elección como fuente de información para este artículo, ya que es la única revista que apuesta abiertamente y con estos términos por un turismo de proximidad. 


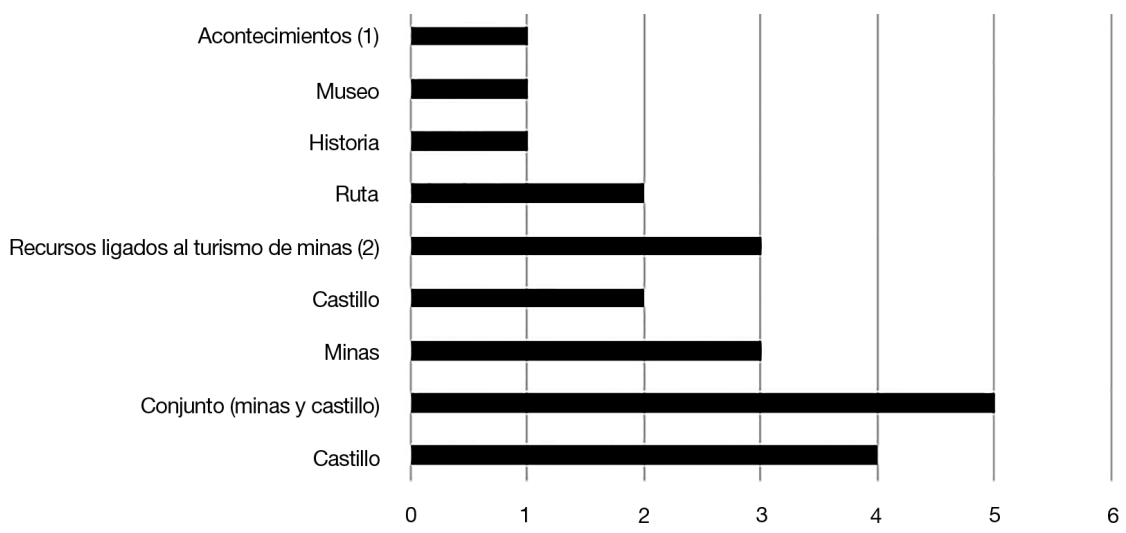

Figura 4. Citaciones de Cardona en la revista Descobrir Catalunya (1997-2014).

Fuente: elaboración propia.

(1) Carnaval.

(2) Patrimonio geológico, camino de la sal, Geoparque.

aparición de la revista coincidió con la puesta en marcha del turismo en la antigua mina de Cardona). Segundo, se han encontrado veintidós citaciones distribuidas en dieciséis números. Tercero, además de lo dicho anteriormente, en lo que llevamos de 2014 (hasta julio) ya han aparecido seis referencias exclusivamente de Cardona. Y cuarto, las citaciones se centran, principalmente, en el castillo y el recinto minero, bien de forma individual o bien en conjunto (Figura 4).

De esto se concluye que el conjunto minero sigue siendo el recurso más conocido de Cardona, junto con el castillo, y que uno y otro se complementan mutuamente. Es decir, la visita de la mina serviría para atraer a los turistas y después, los demás recursos completarían la oferta global de Cardona, de lo que podría derivarse que se plantearan actuaciones para alargar la estancia del visitante en el municipio. Por ejemplo, y por poner un caso, el análisis realizado muestra que a raíz de la celebración del tricentenario de la Guerra de Sucesión Española (1714-2014)2, numerosas propuestas turísticas han sido desarrolladas con el castillo de Cardona como protagonista. Los turistas que visitan Cardona por este motivo son, en su mayoría, turistas de proximidad, y dichas propuestas, aunque tengan como temática principal la historia en torno al castillo, intentarían atraer al público que se desplaza a Cardona hacia la montaña de sal. Esto es interesante por cuanto la puesta en marcha de una oferta turística basada en una antigua explotación minera, puede verse cues-

2. El número 196 (junio de 2014) es un monográfico sobre este tema con el título (traducido del catalán): Los escenarios clave de la Guerra de Sucesión. Sin embargo, en el artículo dedicado a Cardona, «La despedida a un baluarte inexpugnable», no aparece ninguna referencia a la mina de sal. 
tionada en la medida que, como ya se ha comentado, este patrimonio estaría en un segundo plano con relación a otros recursos con un valor histórico y patrimonial más universalmente aceptado.

\section{Conclusiones}

No cabe duda de que en un contexto en el que ciertas actividades industriales y mineras han dejado de ser el principal pilar económico de muchos territorios, la recuperación de un patrimonio en forma de elementos materiales o tangibles (edificios, instalaciones y maquinaria) e intangibles (cultura, historia y paisaje) que durante mucho tiempo ha permanecido en el olvido, se ha convertido en el eje de nuevas estrategias de desarrollo a un nivel escalar muy cercano al territorio. Y lo que resulta más interesante es que este proceso de recuperación se enmarca en un contexto de expansión de un turismo cultural, que precisamente por ser muy heterogéneo y diverso, nadie niega que ha de superar las tradicionales fronteras que muy a menudo se han impuesto para considerar unos elementos como "patrimonio" y descartar otros. Además, de igual manera a como se ha ido ampliando la noción de "patrimonio", también lo ha hecho la idea de qué hacer con él: de primar una cierta visión «monumental» (un resto o vestigio industrial como un elemento aislado y singular en un lugar concreto pero sin ir más allá) a concebirlo como una estrategia viable dentro de un esquema de política de desarrollo territorial y urbano (Benito, 2012; Benito y Alonso, 2012).

En esta línea, y además de la voluntad expresa de revalorizar este patrimonio de «segundo nivel», lo que hay que tener también presente es comprobar dos aspectos: primero, ver hasta qué punto los instrumentos, las iniciativas y las acciones que se implementen son capaces de responder a las expectativas generadas y a un objetivo básico como es el de generar prosperidad y bienestar en lugares donde la anterior estructura productiva ha desaparecido y ha dejado un escenario de incertidumbre, crisis económica, demográfica y de identidad. Así, desde la geografía y otras ciencias sociales se abriría un campo de investigación muy interesante en cuanto a temas como la relación entre patrimonio específicamente minero y un proceso de desarrollo local en territorios en declive, así como también entre patrimonio cultural (en genérico) y ordenación del territorio. Y esto resulta más importante después de constatar cómo algunos de los centros turísticos de patrimonio minero más destacados experimentan descensos significativos del volumen de visitantes, después de haber alcanzado sus máximos históricos. A pesar de estos datos, creemos que el objetivo planteado de que el turismo de proximidad puede contribuir a la revalorización del patrimonio local es plenamente vigente, quizás porque este mismo turismo puede ser menos vulnerable a contextos de crisis como el actual.

Por su parte, y retomando esto último, el segundo aspecto se refiere a la posibilidad de establecer conexiones entre el turismo basado en el patrimonio minero y el turismo de proximidad. Con relación a esto, este artículo ha pretendido abordar un tema que a pesar de que en nuestro país no ha recibido a día de hoy la atención que seguramente se merece, vemos también que puede 
tener una muy evidente conexión con el caso de estudio de Cardona. El análisis de sus «apariciones» en la revista Descobrir Catalunya — en tanto que revista que apuesta claramente por la difusión del conocimiento geográfico y turístico de un territorio entre sus propios habitantes - puede ser una opción metodológica muy viable; la tesis de comprobar hasta qué grado Cardona ha ganado en presencia a medida que ha consolidado su oferta turística o si, por el contrario, permanece en un nivel inferior respecto a otras ofertas y territorios con mayor poder de atracción, creemos que puede ser perfectamente analizada con este tipo de fuentes de información de carácter más "popular». Del análisis efectuado se constata cómo el municipio en cuestión parte con la desventaja de localizarse en una comarca que, desde el punto de vista turístico, no ha desarrollado todo el potencial que se le presupone y, de hecho, la presencia de unos determinados territorios es casi una constante en la revista, mientras que otros, entre ellos El Bages, apenas merecen una atención residual. Además, podría decirse también que el turismo basado en el patrimonio industrial sigue esta presencia más bien minoritaria, puesto que se han contabilizado un total de cuarenta y cinco apariciones para todo el ámbito territorial de la revista, la mayoría en forma de artículos y propuestas de rutas. Sea como sea, es de esperar que la reciente aparición en el mercado de otra revista con un objetivo más específicamente «de proximidad» - Experiències - contribuya en un futuro próximo a proporcionar más información que ayude a comprender mejor la relación del turismo de proximidad con determinadas iniciativas turísticas basadas en patrimonios con un menor reconocimiento.

A pesar de que la comarca de El Bages presenta un panorama turístico no demasiado optimista, Cardona se ha erigido en uno de sus focos turísticos con más peso y es, además, dentro del reducido número de antiguos centros mineros de España que se han reconvertido al turismo, uno de los pocos que arrojan cifras de visitantes relativamente importantes y que se gestionan por sí mismos con los ingresos obtenidos de su actividad diaria. Es por ello que este caso de estudio resulta bastante útil como base de una línea de investigación que contribuya a una mejor comprensión del papel que puede tener el turismo de patrimonio minero en territorios con una escasa tradición turística. Sin embargo, en este caso en concreto, para las autoridades locales, el reto continúa siendo el de aumentar el volumen de personas que habiendo ido al parque minero alargan después la estancia hacia el centro histórico de la ciudad. Y es que la mayoría de la gente que actualmente se desplaza a Cardona solo visita el antiguo recinto minero y el castillo-parador. Quizás la idea del turismo de proximidad no se haya desplegado todavía en toda su amplitud, a la vez que no habría que olvidar que es un recurso patrimonial más difícil de «vender» que otros (Pachá, 2013). La distancia geográfica juega un papel importante en más de un aspecto, pero tratándose de un turismo bastante minoritario, lo es sobre todo en la promoción, tanto dentro de los límites regionales de Cataluña como fuera de ella (Prat y Díaz Soria, 2014).

Finalmente, un último apunte relativo a la cuestión del paisaje y la herencia que ha supuesto la actividad minera en las seis décadas que estuvo presente en Cardona; puesto que uno de sus posibles atractivos es, precisamente, el hecho de 
poder explicar el paisaje local radicalmente transformado con la «inserción» de dos escombreras, y viendo que la más grande está en vías de desaparición — por los trabajos de obtención de sal que se llevan a cabo- y que también hay planes para que a medio plazo suceda lo mismo con la otra, ¿no hubiera sido mejor dejar intacto el entorno después del cierre de la mina de potasa, por mor de lo diferente e inhabitual que es un paisaje con estas características? Obviamente, hay que reconocer que esta es una pregunta arriesgada en la medida que es difícil valorar lo que se derivaría de una actividad — la turística- - y lo que está suponiendo actualmente la obtención de sal, en cuanto a la creación de riqueza en un municipio que, como ya se ha descrito, está viviendo un declive demográfico lento pero sin pausa. De hecho, en ningún momento se ha planteado la posibilidad de dejar las dos escombreras (o al menos una) que sirvieran de testimonio del pasado minero más inmediato, sino que la voluntad expresa es recuperar el aspecto original del valle salino, previo a la irrupción de la minería moderna e industrial. Pero, ¿por qué no pensar en la posibilidad de que los paisajes mineros «auténticos» puedan llegar a ser una oportunidad para crear entornos en los que el patrimonio tenga un papel decisivo? (Saurí y Llurdés, 1995).

\section{Referencias bibliográficas}

Aguas, Jean-Christophe y GouyetTe, Bruno (2011). «L'invention d'un tourisme de l'ordinaire. L'exemple des Promenades urbaines». Espaces, tourisme et loisirs, 292, 8-13. Álvarez, Miguel Ángel (2007). Arqueología Industrial. El pasado por venir. Gijón: CICEES-INCUNA (colección La Herencia Recuperada, 4).

Baudrillard, Jean y Guillaume, Marguerite (1994). Figures de l'altérité. París: Descartes \& Cie.

Benito, Paz (2002). "Patrimonio industrial y cultura del territorio». Boletín de la Asociación de Geógrafos Españoles, 34, 213-228.

- (2012). «Territorio, paisaje y herencia industrial: debates y acciones en el contexto europeo». Documents d'Anàlisi Geogràfica, 58 (3), 443-457.

Benito, Paz y Alonso, Pablo (2012). «Industrial heritage and place identity in Spain: from monuments to landscapes». Geographical Review, 102 (4), 446-464. <http://dx.doi.org/ 10.1111/j.1931-0846.2012.00169.x>

Bessière, Jacinthe (2000). «Valeurs rurales et imaginaire touristique». En: Amirou, Rachid y Bachimon, Philippe (dir.). Le tourisme local. París: L'Harmattan, 71-92.

Boschma, Ron (2004). «Proximité et innovation». Économie rurale, 280, 8-24.

Canalís, Xavier (2009). «Turismo de proximidad, una tendencia coyuntural que plantea un conflicto de intereses». Hosteltur.com. <www.hosteltur.com/60622_turismo-proximidad-tendencia-coyuntural-plantea-conflicto-intereses.html> [consulta: 6 de julio de 2014].

Cànoves, Gemma; Villarino, Montse; Blanco, Asunción; de Uña, Elena y EspeJo, Cayetano (eds.) (2014). Turismo de interior: renovarse o morir. Estrategias y productos en Catalunya, Galicia y Murcia. Valencia: Publicacions de la Universitat de València.

CaÑIZARes, Maria del Carmen (2011a). «Protección y defensa del patrimonio minero en España». Scripta Nova. Revista Electrónica de Geografía y Ciencias Sociales, XV (361). <www.ub.edu/geocrit/nova.htm> [consulta: 6 de julio de 2014]. 
- (2011b). «Patrimonio, parques mineros y turismo en España». Cuadernos de Turis$m o, 27,133-153$.

Colom, Mercè (2012). «Las marcas turísticas territoriales como herramienta de promoción de Cataluña». Póster presentado en el XIII Coloquio de Geografía del Turismo, Ocio y Recreación (Turismo y Territorio. Innovación, renovación y desafios). Asociación de Geógrafos Españoles. Barcelona, 14-16 de junio.

Coma, Josep (2014). «Nuevos lugares y productos turísticos en la Cataluña interior. Los productos que no aparecen en el mapa de destinos turísticos catalanes». En: López Palomeque, F. y Cànoves, G. (eds.). Turismo y Territorio. Innovación, renovación y desafios. Valencia: Tirant Humanidades, 415-428.

Dewailly, Jean Michel y Flament, Emile. (1993). Dossier des images économiques du monde. París: Sedes.

DíAz, Inmaculada y Llurdés, Joan Carles (2013). «Reflexiones sobre el turismo de proximidad como una estrategia para el desarrollo local». Cuadernos de Turismo, 32, 65-88.

Díez, Daniel (2012). «Los turismos de interior: un enfoque desde la dimensión de las modalidades turístico-recreativas». Documents d'Anàlisi Geogràfica, 58 (3), 373-396.

Edwards, James Arwel y Llurdés, Joan Carles (1996). «Industrial heritage: mines and quarries». Annals of Tourism Research, 23 (2), 341-363. <http://dx.doi.org/10.1016/0160-7383(95)00067-4>

FERnÁNDEZ, Esther (2006). «De tesoro ilustrado a recurso turístico: el cambiante significado del patrimonio cultural». Pasos. Revista de Turismo y Patrimonio Cultural, 4 (1), 1-12.

García, Francisco Javier; Delgado, Aquilino y Felicidades, Jesús (2013). «El turismo en la cuenca minera de Riotinto». Cuadernos de Turismo (31), 129-152.

Govers, Robert; Van Hecke, Etienne y Cabus, Peter (2008). «Delineating Tourism: Defining the Usual Environment». Annals of Tourism Research, 35 (4), 1053-1073. <http://dx.doi.org/10.1016/j.annals.2008.09.001>

Instituto del Patrimonio Cultural de España (IPCE) (2011). Plan Nacional de Patrimonio Industrial. Madrid: Ministerio de Educación, Cultura y Deportes.

Llurdés, Joan Carles (1994). «El turismo industrial y la estética de los paisajes en declive». Estudios Turísticos, 121, 91-107.

- (1995). «Les activitats turístiques de nova creació com una estratègia de reconversió econòmica i ambiental per a zones en decadència. L'exemple del turisme de patrimoni miner a Cardona (Bages)». Documents d'Anàlisi Geogràfica, 27, 75-95.

- (1997). «El turismo de patrimonio industrial y minero. Una experiencia de turismo interior inexplorada». En: Valenzuela, Manuel (coord.). Los turismos de interior: el retorno a la tradición viajera. Madrid: Ediciones de la Universidad Autónoma de Madrid (Colección de Estudios, 52), 197-206.

- (2001). "Heritage tourism and textile 'model villages': the case of River Park, Barcelona, Spain». Tourism Recreation Research, 26 (1), 67-71.

López Palomeque, Francisco y Font, Xavier (2014). «Evolución reciente de la gestión turística local en los espacios de interior de Cataluña». En: López Palomeque, F. y CÀnoves, G. (eds.). Turismo y Territorio. Innovación, renovación y desafíos. Valencia: Tirant Humanidades, 479-490.

MagÁN, José María Aristóteles (2005). «El patrimonio industrial: el gran olvidado en la legislación española sobre bienes culturales». En: Álvarez, Miguel Ángel (coord.). Didáctica e interpretación del patrimonio industrial. Gijón: Incuna (Colección Los ojos de la memoria, 5), 107-116. 
Michel, Frank (2012). «L'ailleurs chez soi : tourisme de proximité et exotisme à domicile». L'Autre Voie (8). <www.deroutes.com> [consulta: 6 de julio de 2014].

Montilla, Raúl (2014). «Patrimonio, ¿Hasta dónde conservamos?». La Vanguardia. 15 de marzo, 34-35.

Nogué, Joan (ed.) (2007). La construcción social del paisaje. Madrid: Biblioteca Nueva.

- (2008). "Al margen: Los paisajes que no vemos». En: Maderuelo, Javier (ed.). Paisaje y territorio. Madrid: ABADA, 181-202.

OMT (Organización Mundial del Turismo) (2008). «Entender el turismo: Glosario básico». Organización Mundial del Turismo. <http://media.unwto.org/es/content/ entender-el-turismo-glosario-basico> [consulta: 26 de noviembre de 2014].

Pachá, Francis (2013). «Turismo industrial, en construcción». Savia, 24 (octubre), 50-53.

PARdo, Carlos Javier (2002). «Rutas y lugares de patrimonio industrial en Europa: consideraciones sobre su aprovechamiento turístico». Espacio, Tiempo y Forma, serie VI, Geografia, 15, 69-94.

- (2008). Turismo y patrimonio industrial. Un análisis desde la perspectiva territorial. Madrid: Síntesis.

- (2010). «El patrimonio industrial en España: análisis turístico y significado territorial de algunos proyectos de recuperación». Boletín de la Asociación de Geógrafos Españoles, 53, 239-266.

PRAT, Josep Maria (2012). «El desarrollo territorial del turismo industrial en Cataluña (1980-2010)». Estudios y Perspectivas en Turismo, 21 (5), 1173-1189.

Prat, Josep Maria y CÁnoves, Gemma (2012). «El patrimonio industrial como dinamitzador del territorio. El caso del ecomuseo La Farinera, en Castelló d'Empúries (Cataluña)». Documents d'Anàlisi Geogràfica, 58 (1), 79-100.

Prat, Josep Maria y Diaz Soria, Inmaculada (2014). "La repetición de visitas en el turismo industrial. Aplicación de un modelo de ecuaciones estructurales en el Bages y el Berguedà». Documents d'Anàlisi Geogràfica, 60 (2), 349-368. <http://dx.doi.org/10.5565/rev/dag.88>

Prentice, Richard; Witt, Stephen y Hamer, Claire (1998). «Tourism as experience. The case of heritage parks». Annals of Tourism Research, 25 (1), 1-24. <http://dx.doi.org/10.1016/S0160-7383(98)00084-X>

Puche, Octavio; Hervás, Ana y Mazadiego, Luis Felipe (2011). «El patrimonio histórico minero-metalúrgico en España: su impacto en el turismo cultural». De Re Metallica, 17, 27-46.

Saurí, David y Llurdés, Joan Carles (1995). «Embellishing nature: the case of the Salt Mountain project of Cardona, Catalonia, Spain». Geoforum, 26 (1), 35-48. <http://dx.doi.org/10.1016/0016-7185(95)00016-E>

SEDPGYM (Sociedad Española para la Defensa del Patrimonio Geológico y Minero) (2008). Carta de El Bierzo del patrimonio industrial minero (27-06-2008). <http:// www.sedpgym.es/index.php?option=com_content\&view=article\&id=71: cartadel-bierzo\&catid $=54$ :espana\&Itemid $=84>$ [consulta: 26 de noviembre de 2014] .

Uriely, Nathan (2005). "The tourist experience. Conceptual developments». Annals of Tourism Research, 32 (1), 199-216. <http://dx.doi.org/10.1016/j.annals.2004.07.008>

URRY, John (1990). The Tourist Gaze: leisure and travel in contemporary societies. Londres: Sage.

Urry, John y Larsen, Jonas (2012). The Tourist Gaze 3.0. Londres: Sage (3a edición). 